\title{
A NEW DESIGN OF BLADE FOR SMALL HORIZONTAL-AXIS WIND TURBINE WITH LOW WIND SPEED OPERATION
}

\author{
Paramet Pathike, Thanad Katpradit, Pradit Terdtoon and Phrut Sakulchangsatjatai
}

Department of Mechanical Engineering, Faculty of Engineering, Chiang Mai University, 50200, Thailand

Received 2012-10-09, Revised 2013-03-31; Accepted 2013-07-04

\begin{abstract}
In Thailand, the average wind speed throughout the country is comparatively low for normally-available wind turbine. Designing of a new blade suitable for applications in the average wind speed of 3-7 m sec is, thus, a main objective of this study. High torque has to be obtained properly to generate electricity. In order to design and evaluate performance, our mechanical model has been developed based on Blade Element Momentum theory and, the model is consequently employed to determine the optimized blade shape under constrains that are rotor diameter of wind turbine is not higher than $3 \mathrm{~m}$, design wind velocity is $6 \mathrm{~m} \mathrm{sec}^{-1}, 12$ and $24 \mathrm{~V}$ battery chargers respectively. New wind turbine blade manually made from fiberglass (GRP) with safety factors of 4 (for $12 \mathrm{~V}$ battery) and 2.8 (for $24 \mathrm{~V}$ battery). Experimental study is conducted by testing both of commercial blades and our new blade with a specific wind turbine set. We found that, at designed wind velocity, the efficiency of our new wind turbine blade of $27 \%$ is obtained while that of the commercial wind turbine is only $16 \%$.
\end{abstract}

Keywords: Small Wind Turbine, Low Wind Speed Wind Turbine, Wind Turbine Blade

\section{INTRODUCTION}

In Thailand, there is low potential of wind energy (DAEDE, 2010) especially in the widely well-known attractive place of Chiang Mai (Chaichana and Chaitep, 2010) where the average wind velocity is only $6 \mathrm{~m} \mathrm{sec}^{-1}$. Hence, extraction of energy from wind is mostly obtained by using small wind turbine in order to locally produce electrical energy. Based on power output, small wind turbines can be divided into three categories: micro ( $<1 \mathrm{~kW}, \mathrm{R}<1.5 \mathrm{~m})$; mid-range $(1 \mathrm{~kW}-20 \mathrm{~kW}, \mathrm{R} \approx 1.5-5 \mathrm{~m})$; and mini (20-50kW, $\mathrm{R} \approx 5 \mathrm{~m}+$ ) (Clausen and Wood, 1999). But, recent commercial wind turbines have been designed for suitable use with wind velocity of $8-15 \mathrm{~m} \mathrm{sec}^{-1}$ and in such environment, their components are fixed and cannot be adapted to their varied environmental conditions, thus, they cannot operate at their highest efficiencies. Although efficiency can be improved by increasing wind turbine blade length to generate electricity, the overall size of turbine will also increase and construction cost will higher. This dilemma always happens in the application aspect of wind energy. Thus, it is better to improve by increasing torque of wind turbine. This research consequently attempts to develop a simulation of both wind turbine efficiency and higher torque. The simulation is based on the Blade Element Momentum theory (BEM) which is a classical method to calculate the induced velocities on wind turbine blade and employed to determine the optimized parameters (Jonkman, 2003). Airfoil shape is modified to improve lift force and consequently torque at low wind speed condition (Pathike et al., 2011). In the analysis and design of our new wind turbine, complexity for construction is considered to be solved while this does not affect electrical capacity generated.

\section{MATERIALS AND METHODS}

The designing methodology of wind turbine blade can be mainly divided into three parts; establishment of a 
mathematical model to predict the operating performance, determination of blade parameters and experiments for wind turbine blade operating.

\subsection{Mathematical Model}

The mathematical model to design wind turbine is based on the Blade Element Momentum Theory (BEM) (Jonkman, 2003). The Axial Force $\left(\mathrm{F}_{\mathrm{N}}\right)$ and Torque (T) acting on the blades are as follows Equation (1 and 2):

$$
\begin{aligned}
& \mathrm{dF}_{\mathrm{N}}=\mathrm{B} \frac{1}{2} \rho \mathrm{V}_{0}^{2} \frac{(1-\mathrm{a})^{2}}{\sin ^{2} \varphi}\left(\mathrm{C}_{\mathrm{L}} \cos \varphi+\mathrm{C}_{\mathrm{D}} \sin \varphi\right) \mathrm{cdr} \\
& \mathrm{dT}=\mathrm{B} \frac{1}{2} \rho \mathrm{V}_{0} \frac{(1-\mathrm{a})}{\sin \varphi} \frac{\omega \mathrm{r}\left(1+\mathrm{a}^{\prime}\right)}{\cos \varphi}\left(\mathrm{C}_{\mathrm{L}} \sin \varphi-\mathrm{C}_{\mathrm{D}} \cos \varphi\right) \mathrm{rcdr}
\end{aligned}
$$

Moreover, parameter of induction factors can be calculated by using following Equation (3 and 4):

$$
\begin{aligned}
& \mathrm{a}=\frac{1}{\left[\frac{4 \mathrm{~F} \sin ^{2} \varphi}{\frac{\mathrm{Bc}}{2 \pi \mathrm{r}}\left(\mathrm{C}_{\mathrm{L}} \cos \varphi+\mathrm{C}_{\mathrm{D}} \sin \varphi\right)}\right]+1} \\
& \mathrm{a}^{\prime}=\frac{1}{2}\left(\sqrt{1+\frac{4}{\lambda^{2}} \mathrm{a}(1-\mathrm{a})-1}\right)
\end{aligned}
$$

A new empirical relationship between thrust coefficient and induction factor in the case that axial induction factors greater than 0.4 has been established (Buhl, 2005). The BEM theory does not yield reliable results in this range of induction factor. In this case, parameter of induction factor, a, can be calculated by using following Equation (5):

$$
a=\frac{18 \mathrm{~F}-20-3 \sqrt{\mathrm{C}_{\mathrm{N}}(50-36 \mathrm{~F})+12 \mathrm{~F}(3 \mathrm{~F}-4)}}{36 \mathrm{~F}-50}
$$

where, $\mathrm{F}$ is tip loss factor which is defined as following (Jonkman, 2003) Equation (6):

$$
\mathrm{F}=(2 / \pi) \arccos \left(\exp \left\{-\left(\frac{\mathrm{B}(\mathrm{R}-\mathrm{r})}{2 \mathrm{r} \sin (\theta)}\right)\right\}\right)
$$

At any local radius $r$, the combined effect of tensile stress and bending stress can be obtained from Equation (7):

$$
\sigma(r)_{\max }=\frac{F_{c}}{A}+\frac{M_{t} d_{a}}{I_{a}}+\frac{M_{t} d_{b}}{I_{b}}
$$

In this study, the net savings function from is adopted to evaluate and optimize decisions on blade shape selection (Soylemez, 2003) as follows:

$$
\mathrm{N}_{\mathrm{s}}=\mathrm{C}_{\mathrm{P}} \mathrm{HP}-\mathrm{C}_{\text {windturbine }}
$$

Expansion for the net saving function form yields Equation (8-10):

$$
\begin{aligned}
& \mathrm{N}_{\mathrm{s}}=\frac{\text { year }}{1+\mathrm{d}} \mathrm{C}_{\mathrm{P}} \mathrm{HQ}-\left[1-\mathrm{R}_{\mathrm{v}}(1+\mathrm{d})^{- \text {year }}\right] \\
& \left(\mathrm{C}_{\text {windturbine_set }}+\mathrm{C}_{\text {windturbine_blade }}\right) \\
& \mathrm{C}_{\text {windturbine_blade }}=\mathrm{R}\left[\begin{array}{l}
\mathrm{C}_{\text {blade_casting }} \mathrm{B}+\mathrm{C}_{\text {blade_mold }} \\
\mathrm{B}_{\text {chord }} \mathrm{B}_{\text {twist }} \\
+\frac{\mathrm{C}_{\text {blade_root }}}{\mathrm{R}}+\mathrm{C}_{\text {Coating }}
\end{array}\right]
\end{aligned}
$$

Efficiency of a wind turbine can be calculated by following Equation (11):

$$
\eta=\frac{P}{\frac{1}{2} \rho A V^{3}}
$$

Steps for engineering problem solving are shown in Fig. 1. Input parameters for design new wind turbine are explained in next section.

\subsection{Specifications of the Wind Turbine}

\subsubsection{Rotational Speeds}

Rotational speed of electric generator shaft is proportional to electric potential (or voltage). Experimental data of generator (model FD2.7-500 provided by the EL (2010) is shown in Fig. 2. Thus, in case of the battery charger with $12 \mathrm{~V}$ and $24 \mathrm{~V}$ electric potential, the operating rotational speed of electric generator shaft is $100 \pm 5 \mathrm{rpm}$ and $180 \pm 5 \mathrm{rpm}$ respectively. 


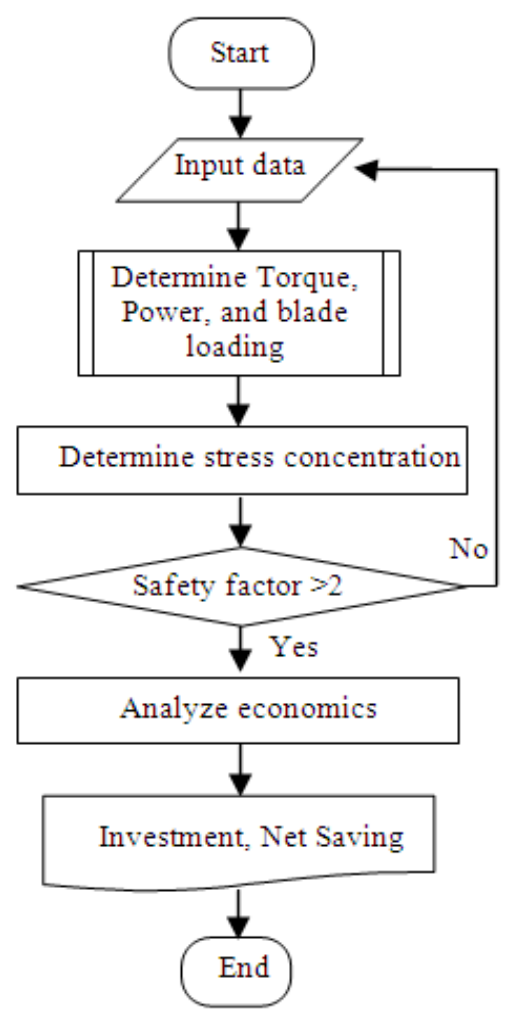

Fig. 1. Flow chart of simulation

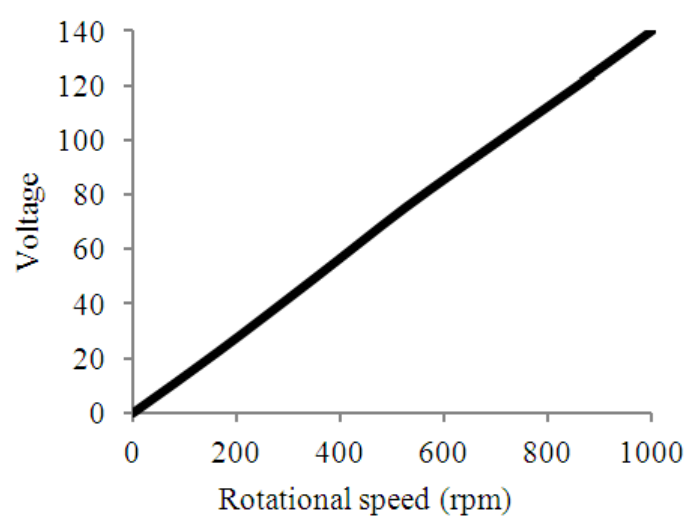

Fig. 2. Testing data of generator of FD2.7-500

\subsection{Airfoil}

Aerodynamic forces (Lift and drag force) are primarily the result of its airfoil geometry and the angle of attack $(\alpha)$ which is the angle between the chord (c) and the direct of the flow. High ratio of $C_{L} / C_{D}$ results to higher power coefficient of the rotor. According to previous studies (Pathike et al., 2011), airfoil of FD2.7500 wind turbine blade' geometry has been developed with its maximum camber, airfoil thickness and their position. For low wind speed, $\mathrm{C}_{\mathrm{L}}$ is improved by $10 \%$ while high $\mathrm{C}_{\mathrm{L}} / \mathrm{C}_{\mathrm{D}}$ can still be obtained. Although this airfoil has been tested in wind tunnel with smaller analogous geometry, in the test it is constructed by analogous larger size than it is used in actual wind turbine according to reduced wind speed in order to maintain low wind speed condition $(\operatorname{Re}=60,000)$. In this study, the improving airfoil is applied and assumed to be constant along blade. The airfoil profile and experimental data are shown in Fig. 3.

\subsection{Blade Parameters}

Since there are many parameters especially in small wind turbines, we have to identify the appropriate range of all of them to design in low wind speed range. According to commercial small wind turbine, we will refer to the size of our available wind turbine. The basic specifications of the turbine are listed as shown in Fig. 4. Additional pitch is the pitch angle which is varied according to blade length (Tip position $=20$ ) and there are five twist styles (S) in this study. Hence, overall pitch of each position along blade length is a combination of the setting angle at tip section and additional tip.

\subsection{Root Section}

Generally, the maximum concentration stresses on wind turbine blade occur from bending moment. In the region of extractable power of wind turbine blade, blade shape cannot be modified to support loading. In this region where wind speed is $12 \mathrm{~m} \mathrm{sec}^{-1}$ (Maximum operating wind speed), the safety factor of 2 is adopted for the material of blade support according to the mechanical properties of Fiberglass Reinforced Plastic (GRP) (Hansman and Wismar, 2003) of the design especially during extreme operating situations. Therefore, in case of stress analysis, root section, which will be connected to hub will be designed to obtain lower stress concentration, is shown in Fig. 5.

\subsection{Experimental Setup}

The objective of this part is to test electric power output obtained from the FD2.7-500 wind turbine when connected with both of our new wind turbine blade and commercialized blade. To obtain conditions of wind passing through our wind turbine blade, a specially designed translating frame has been fabricated and installed on mini truck as shown in Fig. 6. 
Paramet Pathike et al. / Energy Research Journal 4 (1): 1-7, 2013
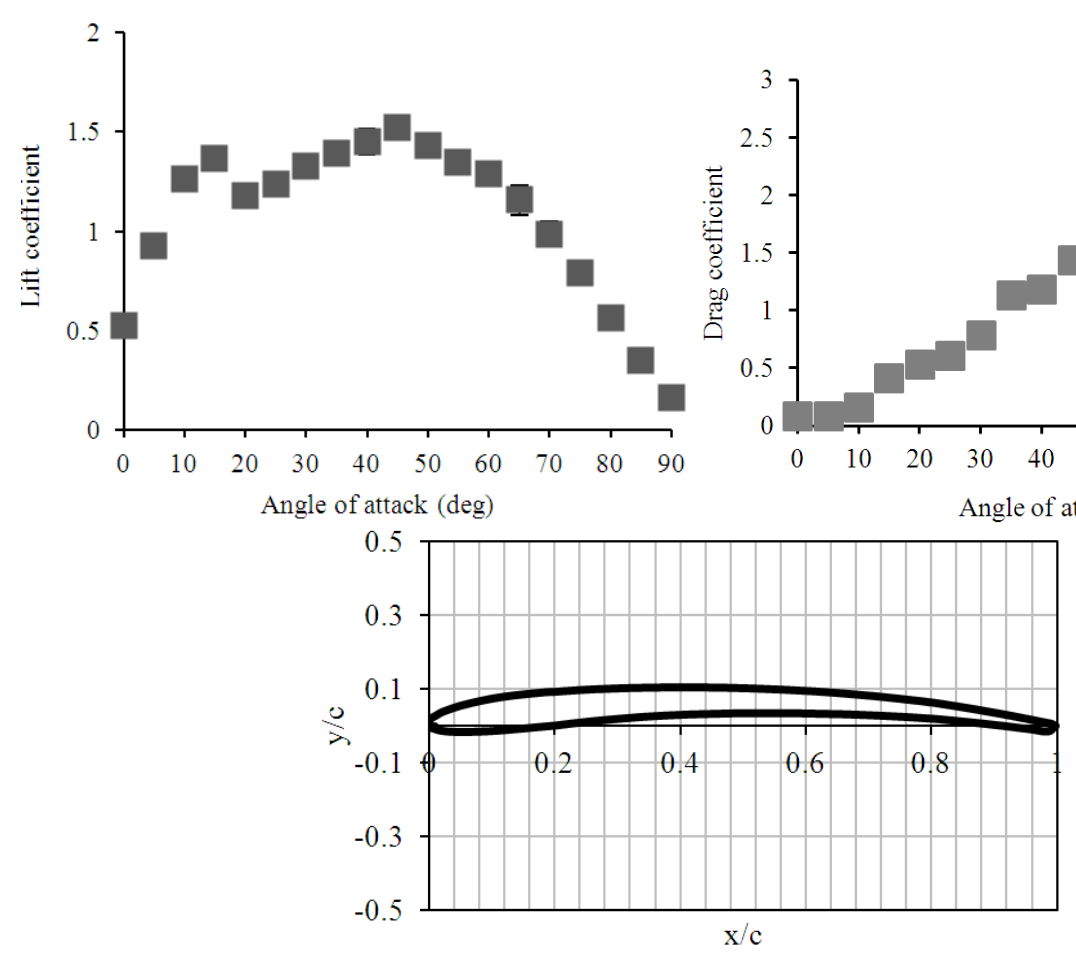

Fig. 3. Aerodynamic coefficients and airfoil profile

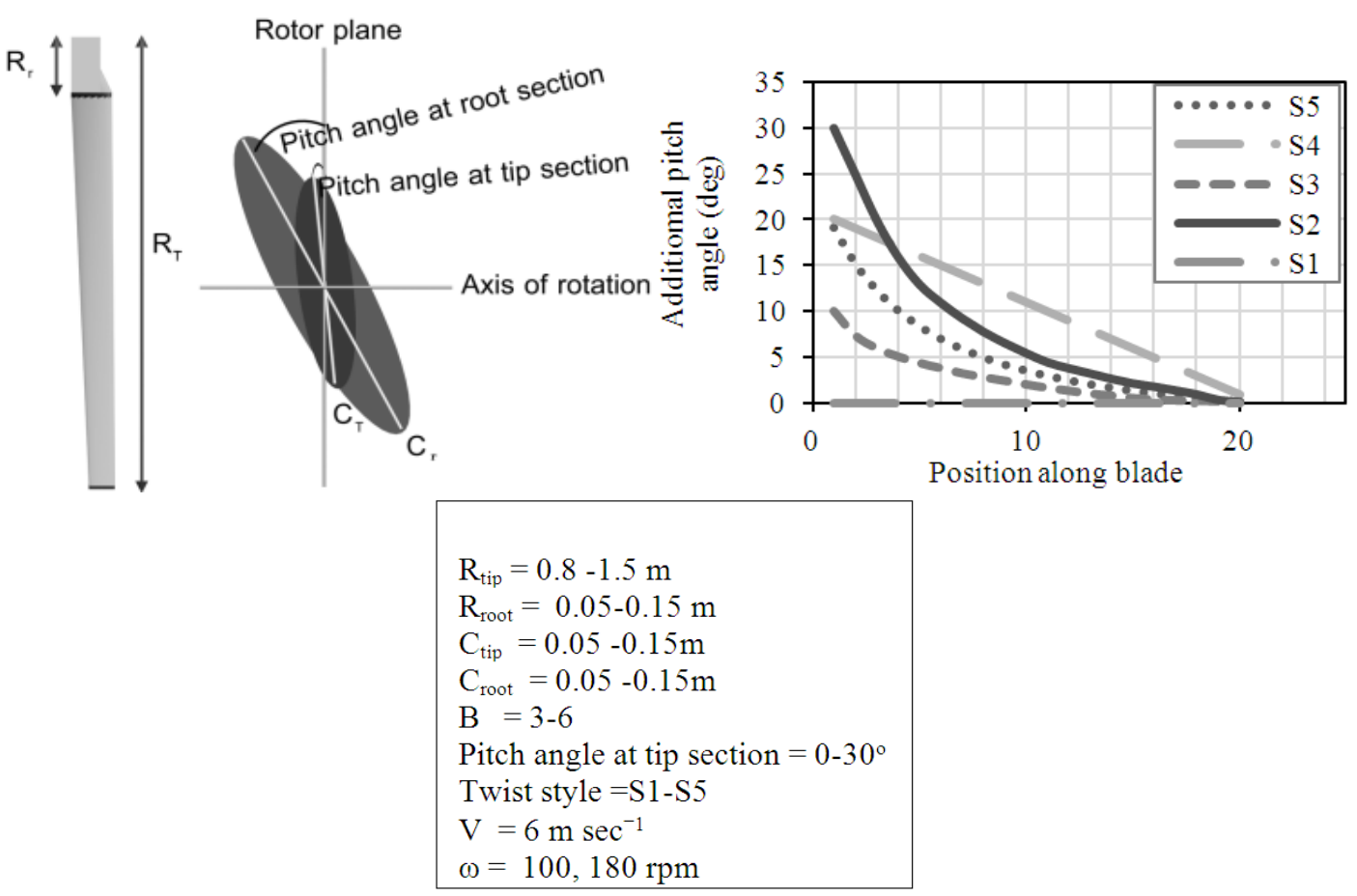

Fig. 4. Rotor parameters 


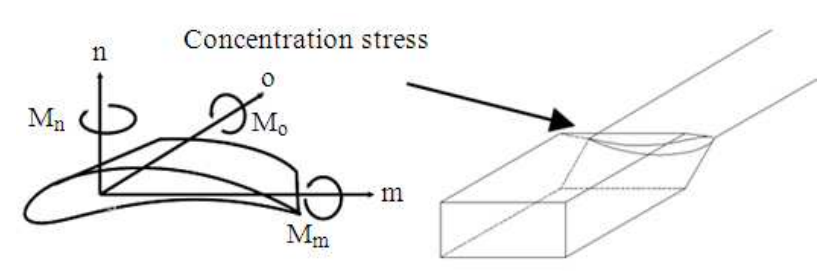

Fig. 5. Stress concentration of new blade

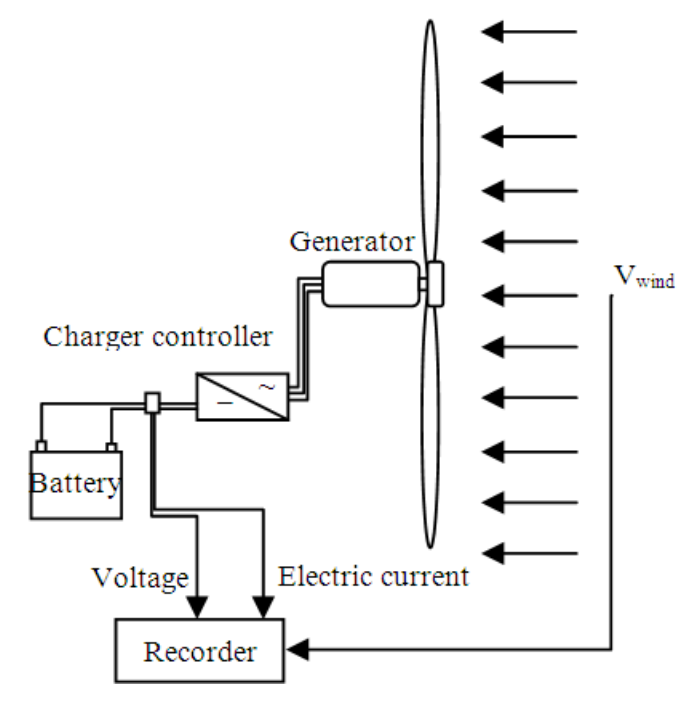

Fig. 6. Illustration of wind turbine blade performance testing

The FD2.7-500 wind turbine set (EL, 2010) consists of; a 3-phase $500 \mathrm{~W}$ synchronous generator, blade length of $1.4 \mathrm{~m}$, root length of $0.15 \mathrm{~m}$, number of blades of 3.The chord length at tip and root of wind turbine blade are $0.11 \mathrm{~m}$ and $0.2 \mathrm{~m}$, respectively. The new wind turbine blades which will be designed in the following section are installed to FD2.7-500 wind turbine set for $12 \mathrm{~V}$ and $24 \mathrm{~V}$ battery chargers. Steps for performance testing of wind turbine blade are as follow;Equipments associated with wind turbine, i.e., current controller, $12 \mathrm{~V}$ battery, anemometer and digital clamp multi-meter are installed on a mini truck since the suitable wind tunnel is not locally available.The truck's velocity starts from the resting position to the required wind speed of 6-9 $\mathrm{m}$ $\sec ^{-1}$. The truck is driven on smooth surface of pavement on highway no. 2121, Thailand to ensure the steady speed of the wind. When the blades are rotating with constant angular velocity, the potential difference (V) and the current (I) are recorded to determine the power output. After that, $24 \mathrm{~V}$ battery is substituted to $12 \mathrm{~V}$ battery and the testing repeats again.

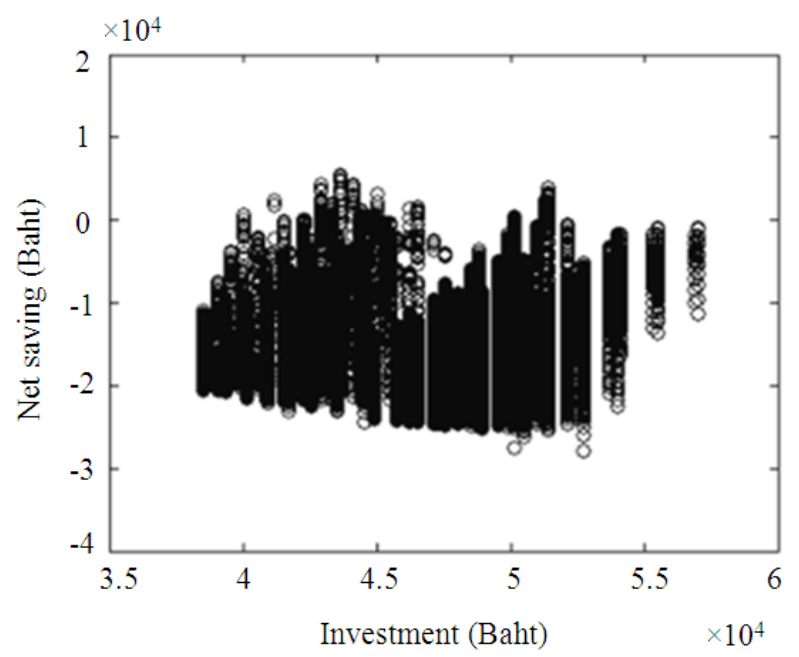

Fig. 7. Simulation result

\section{RESULTS AND DISCUSSION}

Following method shown as flow chart in Fig. 1, the appropriate shape of our new wind turbine can be specified from the tremendous results of the net saving as shown in Fig. 7. Wind turbine blade with the highest net saving (employed as the key indicator of our selection) for the life-time of 10 years is obtained in case of the blade length of $1.3 \mathrm{~m}$, root length of $0.15 \mathrm{~m}$, rotational speed of $180 \mathrm{rpm}$, number of blades of 3 , chord length at tip of wind turbine of $0.06 \mathrm{~m}$, chord length at root of wind turbine of 0.15 $\mathrm{m}$, pitch angle of $7^{\circ} \mathrm{C}$ and non-twisted blade, with the highest power of $235 \mathrm{~W}$.

However, construction of this wind turbine blade shape cannot be locally constructed due to the oversize of the design. The new suitable wind turbine blade shape (NewB) is alternatively chosen in order to reduce the scale wind turbine blade and easier installation. From simulation result, as shown in Fig. $\mathbf{8}$, torque per blade area of our new blade obtained by using new suitable wind turbine blade shape is slightly different from torque obtained by using the previous determined Economic Blade (EcoB) by $3.2 \mathrm{~N} . \mathrm{m} / \mathrm{m}^{2}$ of the Root Mean Squared Error (RMSE). Moreover, power obtained by this type of new suitable wind turbine blade shape is relatively high compared to other blade types in simulation. With new wind turbine parameter set, turbine for $12 \mathrm{~V}$ and $24 \mathrm{~V}$ batteries charging or tip speed ratio are 2.3 and 3.14, respectively, high power and torque are achieved as show on Fig. 9. 


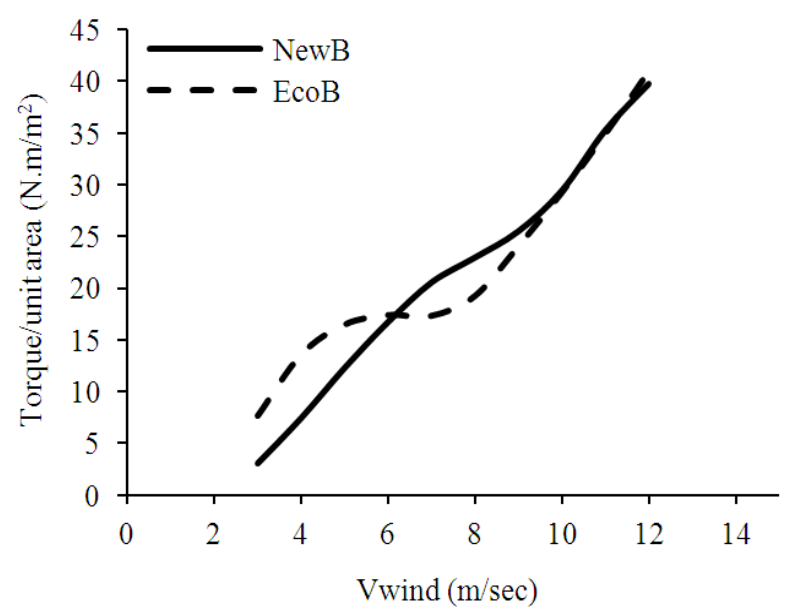

Fig. 8. Relationship of wind velocity and Torque/blade

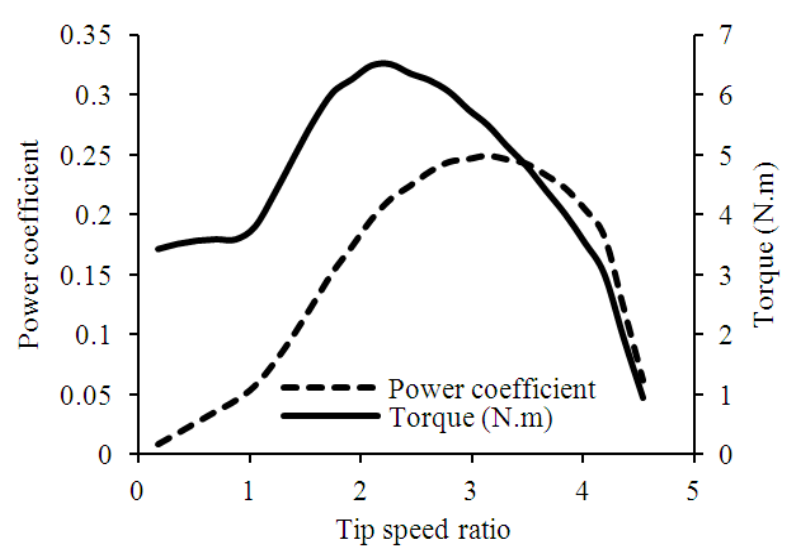

Fig. 9. Simulation results of the new blade

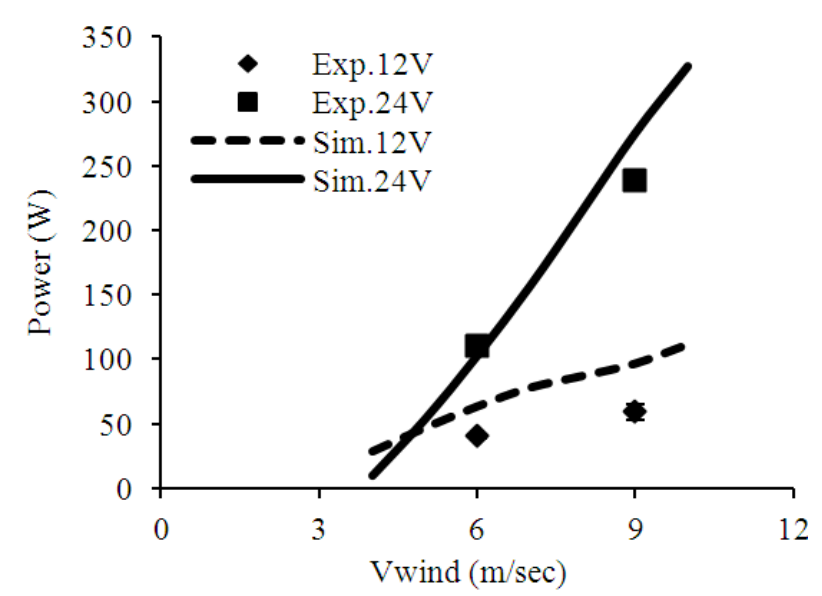

Fig. 10. Comparison of simulation and experimental data

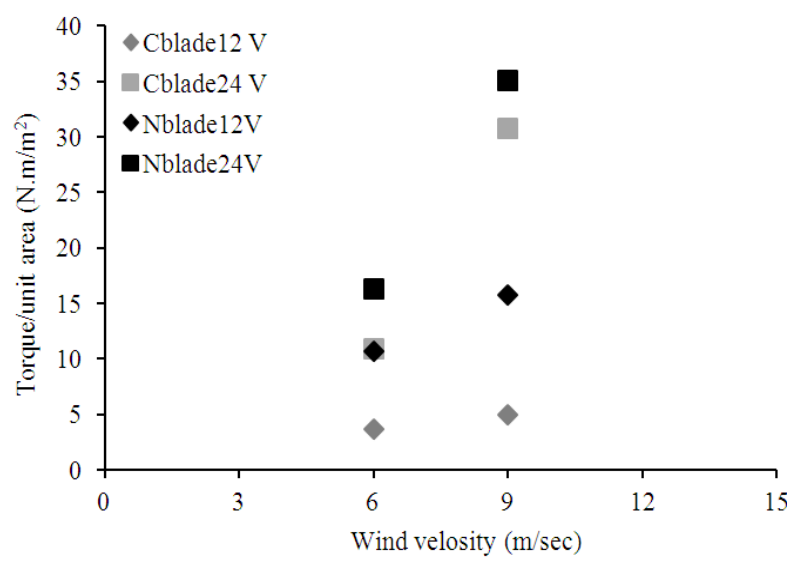

Fig. 11. Testing result of both blade types

New wind turbine blade shape composes of blade length of $1 \mathrm{~m}$, root length of $0.15 \mathrm{~m}$, number of blades of 3 , constant chord length from root to tip of wind turbine of $0.12 \mathrm{~m}$, pitch angle of $20^{\circ}$ and non-twisted blade. As shown in Fig. 10, the simulation results of our newly designed blade are basically closed to its experimental data with the Standard Deviation (STD) of $\pm 14 \%$. The percentage of standard deviation used in this study is normalized with respect to the range of the experimental data. Figure 11 shows a comparison of the output torque per unit area (convert from power) of the Commercialized Blade (ComB) with our newly designed blade. It is found from the $12 \mathrm{~V}$ load system at wind velocities of 6 and $9 \mathrm{~m} \mathrm{sec}^{-1}$ that, powers generated from the new wind turbine blade are 48 and $112 \mathrm{~W}$ and they are higher than commercial wind turbine blade by 60 and $75 \%$, respectively. This maybe because, at this rotational speed of $100 \mathrm{rpm}$, the high lift force coefficient can be obtained. Torque per unit area and energy is consequently high. Torque per unit area obtained from our new wind turbine blade at wind velocities of $6 \mathrm{~m} \mathrm{sec}^{-1}$ and $9 \mathrm{~m} \mathrm{sec}^{-1}$ is higher than that of commercial wind turbine blade by 189 and $218 \%$, respectively. However, in the $24 \mathrm{~V}$ load system, our new wind turbine blade generates less power output than that of the commercial wind turbine blade by 17 and $32 \%$ at wind velocities of $6 \mathrm{~m}$ $\mathrm{sec}^{-1}$ and $9 \mathrm{~m} \mathrm{sec}^{-1}$, respectively. With the same wind velocity, the higher rotational speed of the blade, the higher relative velocity of the blade and the wind is. This is a suitable condition of commercial wind turbine according to its design. However, our new 
wind turbine blade still generates higher torque per unit area in all wind speed operation. It is imply that the wind turbine has easier operation starting. Especially, at wind velocity of $6 \mathrm{~m} \mathrm{sec}^{-1}$, efficiency of our new wind turbine of $27 \%$ is obtained while that of the commercial wind turbine is only $16 \%$. Higher efficiency of our new wind turbine blade comparing to those of commercial wind turbine blades resulted from suitable value selection of various parameters which are consistent to operating condition; the airfoil's pitch angle has been adapted to have attack angle of which high $C_{L} / C_{D}$ is obtained and its inertia is lower resulting in its lighter blade.

\section{CONCLUSION}

Simulation program based on the BEM theory has been successfully established. The new blade is designed according to the program to be applied with FD 2.7-500 wind turbine for low wind speed operation of $6 \mathrm{~m} \mathrm{sec}^{-1}$. It is found that, at wind velocity of $6 \mathrm{~m}$ $\mathrm{sec}^{-1}$, the efficiency of the new wind turbine blade is $27 \%$ while that of the commercial wind turbine blade is only $16.5 \%$. Good agreement between the experimental data and simulation results is achieved with STD of $\pm 14 \%$.

\section{ACKNOWLEDGEMENT}

This research was conducted under the collaboration Graduate School of Chiang Mai University Thailand with the strategic scholarships for frontier research network for the Post doctoral program, the office of the higher education commission.

\section{REFERENCES}

Buhl, Jr. M.L., 2005. A new empirical relationship between thrust coefficient and induction factor for the turbulent windmill state. National Renewable Engry Laboratory.

Chaichana, T. and S. Chaitep, 2010. wind power potential and characteristic analysis of chiang mai, Thailand. J. Mechan. Sci. Technol., 24: 1475-1479. DOI: $10.1007 / \mathrm{s} 12206-010-0415-3$

Clausen, P.D. and D.H. Wood, 1999. Research and Development Issues for Small Wind Turbine. Renew. Energy, 16: 922-927. DOI: 10.1016/j.bbr.2011.03.031

DAEDE, 2010. Wind Resource Map of Thailand. Department of Alternative Energy Development and Efficiency, Thailand.

EL, 2010. Wind Turbine Generator Model: FD2.7-500. Engineo Ltd.

Hansman, H. and H. Wismar, 2003. Composite, ASM Handbook/extraction Polyester Rasin, FB MVU.

Jonkman, J.M., 2003. Modeling of the UAE Wind Turbine for Refinement of FAST_AD. DIANE Publishing, ISBN-10: 1428917411.

Pathike, P., T. Katpradit, P. Terdtoon and S. Chaitep, 2011. Optimum shape of airfoil for small horizontalaxis wind turbine. J. Sci. Technol. MSU.

Soylemez, M.S., 2003. On the thermoeconomical optimization of heat pipe heat exchanger HPHE for waste heat recovery. Energy Conver. Manage., 44: 2509-2517. DOI: 10.1016/S0196-8904(03)00007-4 